\title{
Theory on the formation of working fluid formed by an air jet and a slot sprayer
}

\author{
Alexey V. Palapin ${ }^{1}$, Stanislav I. Roshchupkin ${ }^{2 *}$, Tatiana A. Storojuk ${ }^{1}$ and \\ Anna I. Belousova ${ }^{1}$ \\ ${ }^{1}$ Kuban State Agrarian University named after I.T. Trubilin, Krasnodar, Russia \\ ${ }^{2}$ Sevastopol State University, Sevastopol, Russia
}

\begin{abstract}
The technology of applying the working fluid with protective and stimulating compositions to the surface of leaves of perennial plantings is an important technological operation in the production of products of orchards and vineyards. In the presented work, the formation of working fluid at a separate supply to a slot spraying tip is theoretically considered. Operating parameters of the formation of working fluid formed by an air jet and a slot sprayer after the connection of air ejecting and liquid ejecting flows are also theoretically presented. let us consider the method of calculating colliding jets are cited as well.
\end{abstract}

In solving the problem of complex plant protection, namely spraying, it is necessary to apply working fluid to the plants in a fine form or to the soil surface during mechanized processing or chemical weeding.

The design of well-known sprayers includes a tank for working fluid, a pump for creating pressure, a system for dispersing working fluid, a chassis, a frame, with a trailer or a device for hitching to a tractor and controls.

The work is based on the researches of Palapin Alexey Vitalyevich, $\mathrm{PhD}$ in Engineering $[1,2,3]$.

The technology of processing of perennial plantings and the technological process of spraying itself proceeds as follows. The working fluid for spraying is located in a container where it is constantly mixed to maintain a homogeneous composition. From the tank, the liquid is pumped through the valve system and the dispersion system to sawing tips, and then the sprayers disperse the working fluid to treated objects under the set pressure.

All sprayers contain necessary components and assemblies: pumps, pressure reducing valves, tips of sprayers, and transmission. These mechanisms complicate the design, reduce its reliability and manufacturability, and have a high cost $[1,2]$.

In this regard, we have set the task - to simplify the technological scheme of the sprayer, to increase its reliability, manufacturability, productivity and quality of work, and most importantly, to ensure that the entire structure and its executive elements meet modern agricultural requirements.

* Corresponding author: st.roshchupkin @yandex.ru 
In practice, the technological task of eliminating the above shortcomings is solved by the presence of structural and technological differences between the proposed sprayer and existing structures.

One of the solutions to this problem is theoretical researches. The study of air velocity in a disperser's nozzle is an important technological task.

The air velocity in the disperser's nozzle is determined by the formula:

$$
V_{803}=\frac{G_{603}}{\mu \cdot \tau_{c} \cdot \rho_{603}},
$$

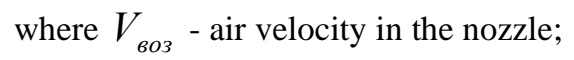

$G_{в о з}$ - air consumption by the sprayer;

$\mu$ - coefficient of consumption;

$\tau_{c}$ - area of exit hole of the nozzle, $\mathrm{m}^{2}$;

$\rho_{в о з}$ - air density in the nozzle, $\mathrm{kg} / \mathrm{cm}^{3}$.

Under known overpressure, the air density is determined from the expression:

$$
\rho_{603}=\frac{P_{603}}{R T_{o}},
$$

since the pressure in the slot sprayer's nozzle is approximately equal to atmospheric pressure, we get the following:

$$
\rho_{\text {воз }}=\frac{P}{R T_{o}} .
$$

When the air-drop jet is formed, not only the air jet coming out of the slot nozzle, but also the air flow entering the spray body from the fan, takes part in the process of liquid ejection $[1,2]$.

At this well-known air velocity from the fan $V_{B в}$ and the cross-sectional area in the sprayer's body $\tau_{\kappa}$, the air flow rate is determined from the expression:

$$
G_{B B}=\rho_{B B} \cdot \tau_{\kappa} \cdot V_{B B}
$$

where $\rho_{B \varepsilon}$ - air density from the fan;

$G_{B 6}$ - air consumption.

The air density from the fan at well-known pressure is determined as the following:

$$
\rho_{\text {sв }}=\frac{P_{0}}{R T_{0}},
$$

where $P_{0}$ - air pressure from the fan;

$R$ - gas constant of air;

$T_{0}$ - air temperature by Calvin.

According to the law of the amount of movement, we have:

$$
G_{B} \cdot V_{B}=G_{B 03} \cdot V_{B 03}+G_{B в}+V_{B в},
$$

where $G_{B}$ - air consumption by the sprayer;

$V_{B}$ - air velocity in the sprayer for ejecting of working fluid.

When mixing the air coming from the slot nozzle with the air from the fan through the sprayer body, two options are possible: 
1) the air velocity from the fan is less than the air velocity from the slot nozzle;

$$
V_{66}<V_{в о з}
$$

2) the air velocity from the fan is equal to or greater than the air velocity from the slot nozzle;

$$
V_{\text {вв }} \geq V_{\text {воз }}
$$

In the first case, the flow of air from the fan will reduce the energy loss of the jet from the slot nozzle, without changing the shape of the plane-parallel jet in whole.

In the second case, it is possible to change the ejection properties of the jet, the study of which is the subject of additional studies.

Also, an important technological mode is the determination of the flow rate of the working fluid of the ejection-slot sprayer.

The flow rate of the working fluid entering the air jet from the slot nozzle is determined from the expression:

$$
G_{\varkappa}=\mu_{\varkappa} \cdot \rho_{\varkappa} \cdot F_{\varkappa} \cdot \sqrt{2 g\left(h_{в a \kappa} \pm h\right)},
$$

where $G_{\varkappa}$ - consumption of working fluid;

$\mu_{\varkappa}$ - coefficient of consumption;

$\rho_{\mathscr{H}}$ - density of liquid;

$F_{\varkappa}$ - area of exit hole of feed tube of the sprayer;

$h_{\text {вак }}$ - velocity pressure generated by the air jet, the pressure of the working fluid, depending on air pressure;

$h$ - position of the container in the system with working fluid relative to the exit hole of the feed tube.

In the case of working fluid entering the air-drop jet from above, the position of the container $h$ is taken with a sign ( + ), in the case of ejection with a sign ( -).

In this case, the velocity pressure is described by the expression:

$$
h_{\text {вaк }}=\frac{V_{s}^{2}}{2 g} .
$$

The flow rate of the working fluid from the circular feed tube is determined from the expression:

$$
\mu_{\varkappa}=\varphi_{\varkappa} \cdot \varepsilon
$$

where $\varphi$ - coefficient of liquid's velocity;

$\varepsilon$ - coefficient of compression.

Compression coefficient for small holes with a sharp edge $\varepsilon=0,64$.

Velocity coefficient is defined on the formula:

$$
\varphi_{\varkappa}=\frac{1}{\sqrt{\alpha+\xi_{\text {ox }}+\xi_{\text {oblx }}}},
$$

where $\alpha$ - Coriolis coefficient, which is used for engineering calculations, is the following: $\alpha=1$;

$\xi_{B x}$ - resistance coefficient at the entering the feed tube;

$\xi_{\text {выl }}$ - resistance coefficient at the exit from the feed tube. 
So, we have $\varphi_{\text {э }}=0,6$, and $\mu_{\Im c}=0,38$.

Theoretical dependence $G_{\varkappa}$ on $F_{\varkappa}$ at different $h_{\text {вак }}$ is presented in Figure 1. As follows from the data obtained, the more is $F_{\varkappa}$, the higher is $G_{\varkappa}$.

Fluid velocity $V_{\varkappa}$ is determined from the expression:

or

$$
V_{\varkappa}=\frac{G_{\varkappa}}{\rho_{\varkappa} \cdot F_{\varkappa}},
$$

$$
V_{\varkappa}=\mu_{\varkappa} \cdot F_{\varkappa} \cdot \sqrt{2 g\left(h_{\text {вак }}+h\right)} .
$$

We consider the method of calculating colliding jets, to determine operating parameters of the formation of the working fluid formed by the air jet and the slot sprayer after the connection of the air ejecting and liquid ejecting flows [1].

One jet flows out of the air channel B and the liquid channel G. Let us assume such a calculation scheme, when the main free and flooded jet of gas, flowing at speed $V_{b}$ from the channel $\mathrm{B}$, which has a cross-sectional area $f_{b}$, acts on the free and flooded jet of liquid flowing from the channel $\mathrm{G}$ with a cross-sectional area $f_{\mathscr{}}$ at speed $V_{\varkappa}$ (Figure 1).

Denote the angle between the jets by $\alpha$. The values of pressure, flow rate, and velocity of the mixed jet are denoted respectively $p_{c} ; Q_{c} ; V_{c}$.

The angle between jets is denoted as $\alpha$, the angle between the air-drop jet and the centerline of the mixing chamber is denoted as $\beta$ (the angle of rotation of the air-drop jet after collision of jets).

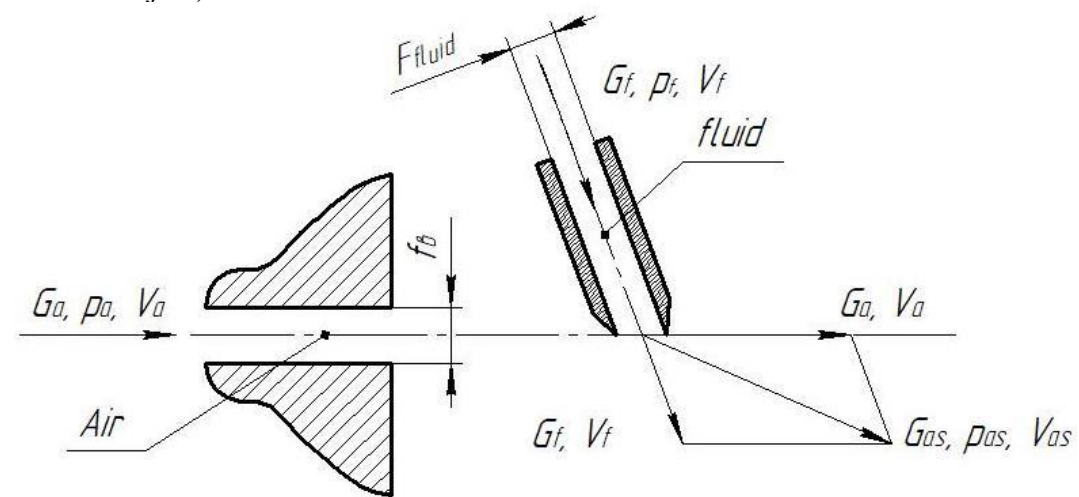

$G_{\varepsilon}, G_{\dddot{\prime}}, G_{c}$ - mass air rate, liquid, mixtures;

$p_{\varepsilon}, p_{\text {эc }}, p_{c}$ - air pressure, liquid, mixtures;

$V_{B}, V_{\dddot{ }}, V_{c}$ - velocity of air, liquid, mixtures;

$f_{B}, f_{\varkappa}, f_{c}$-cross-sectional area of the air liquid jet and the air-drop jet.

Fig. 1. Scheme of air-drop jet parameters calculation

We use the theory of potential flow of ideal fluid for the analysis. We apply a number of assumptions concerning the operation of a physical process [3]:

- direction of the regulating flow and its dimensions are determined by the force interaction of jets only in the area located near the edges of channels from which the fluid 
flows. Further, the resulting jet is considered formed and disperses as turbulent. This circumstance allows us to apply the relations for the resulting jet that are valid for a single turbulent submerged jet;

- static pressure of interaction of jets in the whole area is not changed;

- cross-section of liquid and air is considered at small pressure differences, so the compressibility of working medium can be neglected and the isochoric process can also be accepted as $p_{в}=$ const $и p_{\varkappa}=$ const

- flat flow.

Under the above assumptions, we can apply the theorem on the amount of motion and continuity of the flow for the resulting jet.

Based on the analysis of existing designs of fan sprayers for the treatment of perennial plantings and their technological schemes of operation, mathematical dependences of the speed of movement of the working fluid particle in air flow created by the fan of the proposed sprayer design in the formation of the working fluid formed by the air jet and the slot sprayer were obtained.

\section{References}

1. Palapin A.V. Optimization of parameters and modes of operation of an ultra-lowvolume fan sprayer Palapin A.V. dissertation for the degree of candidate of technical sciences / Krasnodar, 2005

2. Belousov S.V. EXPERIMENTAL RESEARCHES OF PLANT PROTECTION MEANS Belousov S.V., Belousova A.I. B сборнике: MATEC Web of Conferences. 2018 International Conference on Modern Trends in Manufacturing Technologies and Equipment, ICMTMTE 2018. 2018. C. 05002.

3. Belousov S.V. MODERN APPROACH TO CHEMICAL PLANT PROTECTION Palapin A.V., Belousov S.V. British Journal of Innovation in Science and Technology. 2016. T. 1. № 3. C. 13-24. 